\title{
Retrobulbar pressures measured during surgical decompression of the orbit
}

\author{
A Jan Otto, Leo Koornneef, Maarten Ph Mourits, Loes Deen-van Leeuwen
}

Netherlands

Ophthalmic Research Institute, Amsterdam A J Otto

Orbital Center,

University of

Amsterdam

L Koornneef

University Eye Clinic, Utrecht

$\mathrm{M} \mathrm{Ph}$ Mourits

Department of Anaesthesiology, Academic Medical Center, Amsterdam L Deen-van Leeuwen

Correspondence to: A J Otto, $\mathrm{MD}, \mathrm{PhD}$, The Netherlands Ophthalmic Research Institute, PO Box $12141,1100 \mathrm{AC}$,

Amsterdam, the Netherlands.

Accepted for publication 28 June 1996

\begin{abstract}
Aimslbackground-In Graves' ophthalmopathy the increase in volume of intraocular muscles and fat will cause elevated intraorbital pressure. In order to investigate the pressure levels involved, intraorbital pressure, or retrobulbar pressure (RBP) was measured continuously in orbits of patients with Graves' ophthalmopathy during surgical decompression. Methods-Retrobulbar pressure was measured before and during surgical decompression using an intraorbitally applied pressure transducer.
\end{abstract}

Results-In eight patients with dysthyroid optic neuropathy (DON) RBPs between 17 and $40 \mathrm{~mm} \mathrm{Hg}$ were recorded. At the end of the surgical procedure the mean RBP was reduced from $28.7 \mathrm{~mm} \mathrm{Hg}$ to $18.7 \mathrm{~mm}$ $\mathrm{Hg}$, the decrease ranging from 8 to $12 \mathrm{~mm}$ $\mathrm{Hg}$, which showed a high correlation with the starting pressures $(\mathbf{p}<0.001)$. In two cases without DON, pressures were 11 and $9 \mathrm{~mm} \mathrm{Hg}$. Forces exerted by spatula manipulation usually resulted in a RBP level of more than $70 \mathrm{~mm} \mathrm{Hg}$.

Conclusions-This study shows that RBPs are markedly elevated in Graves' ophthalmopathy and that surgical decompression can result in a significant reduction in the intraorbital pressure. Optic nerve dysfunction in Graves' ophthalmopathy may not be caused exclusively by the direct pressure of swollen extraocular muscles upon the optic nerve, but also by a raised RBP. It is hypothesised that the damage inflicted upon the optic nerve can be caused in consequence by RBP induced incarceration of the nerve, compressed by surrounding periosteal lined orbital fat bulging posteriorly into the entrance of the optic canal.

(Br f Ophthalmol 1996;80:1042-1045)

A discrepancy between the volume of the bony orbit and its content is seen in Graves' ophthalmopathy and will probably lead to exophthalmos and visual loss. Protrusion of the eye with displacement of the eyelids and the orbital septum only offer a limited additional space anteriorly due to the rigidity of the connective tissue in septal and suspending ligaments. A relation between intraorbital volume increase and intraorbital or retrobulbar pressure (RBP) has been described earlier in both clinical and experimental settings. ${ }^{1-5}$
A volume induced increase in orbital pressure has always been considered to be the cause of protrusion (and its clinical consequences), but is usually referred to by ill defined terms such as 'orbital tissue consistency', 'orbital tension', or 'orbital rigidity'. Data on 'tensions' or 'orbital compliance' can be estimated indirectly by measuring the posterior displacement of the globe as the result of a certain force exerted upon the eye by an orbitotonometer or orbitotonograph. ${ }^{6-14}$ Surgical 'decompression', by removing parts of the bony orbital wall, is an intervention which leads to favourable results in cases with optic neuropathy, corneal exposure, or cosmetic complaints. ${ }^{15-23}$

Earlier studies, investigating volume induced RBP alterations in monkey orbits, ${ }^{24}$ have shown that reproducible RBP measurements can be performed with a micro pressure transducer introduced intraorbitally. In monkey orbits no differences could be established in pressure levels exploring various sites (intraand extraconically) in the 'steady state' (4-9 $\mathrm{mm} \mathrm{Hg}$ ) or after artificially increasing RBP up to $40 \mathrm{~mm} \mathrm{Hg}$ by means of retrobulbar injection. Since similar experiments cannot be performed in healthy human orbits, we examined RBPs in the orbit of patients with Graves' ophthalmopathy. Elevated RBPs were noted in patients with dysthyroid optic neuropathy (DON), which could be markedly reduced by surgical intervention.

\section{Patients and methods}

Nine patients (age range 48-63; four women, five men) with Graves' ophthalmopathy, in whom surgical intervention was performed, participated in this study. Exophthalmometer readings of the left and right eye showed differences that ranged between 2.5 and $7 \mathrm{~mm}$. Bilateral decompression was performed in six of these cases. Informed consent was obtained from the patients and the protocol of this study was approved by the medical ethics committee of the Faculty of Medicine of the University of Amsterdam.

During surgery, which consisted of a three wall coronal orbital decompression, ${ }^{25} 26 \mathrm{RBPs}$ were recorded in 10 orbits of nine patients. Direct RBP measurements were performed by placing a micro pressure transducer catheter (4 F Honeywell MTCR) in the orbit, behind the globe, and connection to a Princeton Applied Research (PAR) amplifier with a chart recorder. The transducer was inserted retrobulbarly through a trocar needle, and was sutured to the skin after withdrawal of the 


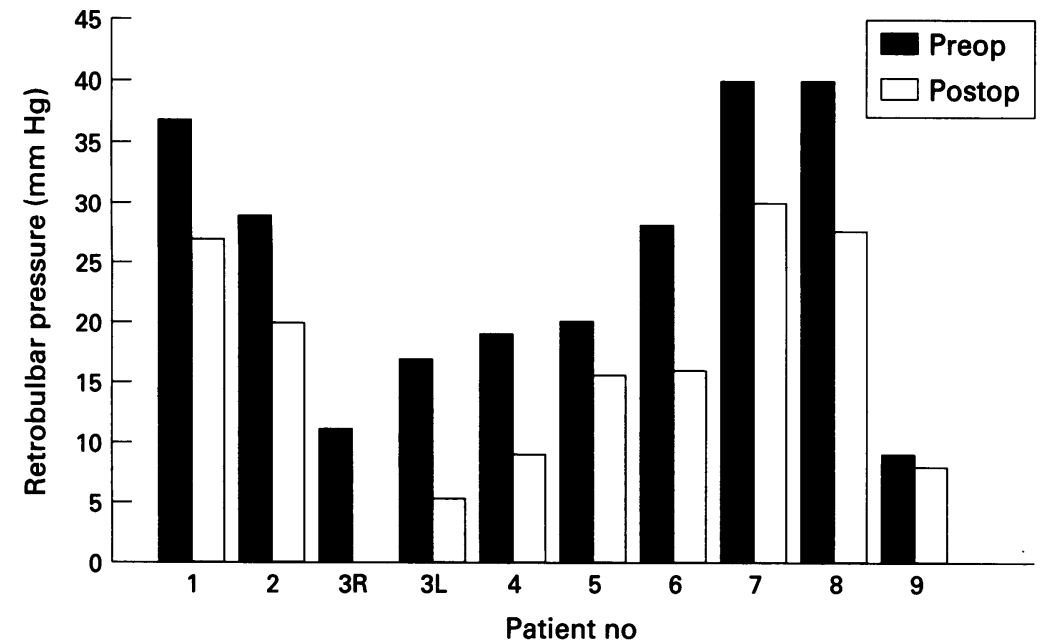

Figure 1 Recorded retrobulbar pressures (RBPs) in nine patients with Graves' ophthalmopathy at the start and at the end of surgical decompression. There were eight orbits with dysthyroid optic neuropathy (mean RBP at the start of surgery $28.7 \mathrm{~mm} \mathrm{Hg}$ and at the end of surgery $18.7 \mathrm{~mm} \mathrm{Hg}$ ) and two with Graves'ophthalmopathy and only cosmetic complaints. The figure shows much lower $R B P$ levels in the two orbits ( $R$ and 9 ) which were operated for rehabilitative reasons.

trocar. In order to investigate the force/ pressure relation during surgery the force exerted upon intraorbital tissues by the surgical spatula was measured. The spatula was mounted with strain gauges (stretch sensitive elements) on both sides for registration of the exerted force. All patients were under general anaesthesia during surgical intervention.

\section{Results}

Eight patients with bilateral and one with unilateral Graves' ophthalmopathy underwent surgical orbital decompression because of progressive loss of vision or progressive loss of visual field.

In these eight patients showing DON, RBP was measured in one orbit before, during, and at the end of the operation. Two more orbits (the contralateral orbit of patient no 3 and the orbit of patient no 9) were decompressed for rehabilitative reasons.

In the eight orbits operated for DON the RBP values, obtained before surgery, ranged between 17 (patient no 3L) and $40 \mathrm{~mm} \mathrm{Hg}$ (patient nos 7 and 8) (mean $28.7 \mathrm{~mm} \mathrm{Hg}$ ). Pre- and postoperative intraorbital pressure levels showed a decrease of the RBPs at the end of surgical decompression averaging $10.0 \mathrm{~mm}$ $\mathrm{Hg}$ (range 9-12 mm Hg) (Fig 1). Before surgery the two orbits without DON showed much lower pressure levels $(8.8 \mathrm{~mm} \mathrm{Hg}$ (patient no 9) and $11.0 \mathrm{~mm} \mathrm{Hg}$ (patient no 3R)]. Because the transducer was transferred from the right to the left orbit in case 3 no further recordings could be made. After decompression the RBP of patient no 9 did not change significantly.

RBP was measured before and after turning down the bicoronal scalp flap and no significant changes in the intraorbital pressure were noted during this surgical manoeuvre. Lowering of the RBP started as soon as incisions in the periorbit were made.

The evoked RBPs exceeded $70 \mathrm{~mm} \mathrm{Hg}$ as a result of a mean exerted force of about $275 \mathrm{~g}$ by an orbital spatula (Fig 2).

\section{Discussion}

Assuming a normal 'steady state' RBP of 3.0$4.5 \mathrm{~mm} \mathrm{Hg}$, the experiments performed in the study described here show that all investigated patients with bilateral Graves' ophthalmopathy had a significantly increased tissue pressure in the orbit. Although no data are available for orbital pressures in healthy humans the normal steady state RBP has been calculated to be 3.0-4.5 based on theoretical calculations obtained by assuming a muscle force of $30 \mathrm{~g}$ applied to the globe. ${ }^{27} 28$ No muscle relaxants were administered which could have an effect on the tone of the recti eye muscles and thus on RBP (Norcuron was used instead of succinylcholine or Flaxedil). We postulate that the physiological homeostatic RBP regulatory mechanism, usually active after retrobulbar injection during intraorbital volume increase by balloon filling, ${ }^{24}$ possibly in the early phase of Graves' ophthalmopathy or tumour growth, may no longer be functioning.

At the end of surgical decompression the RBP already showed a marked reduction in all patients with functional visual impairment. The pressure decrease is highly correlated with the RBPs measured at the start of surgery (Fig 3). Although not necessarily related, most patients lost their sensation of pressure in and around the orbit in the weeks following surgery. We feel that perhaps in the orbit a new pressure equilibrium is re-established, although the mechanism of pressure regulation is not known. In our experience it mostly takes

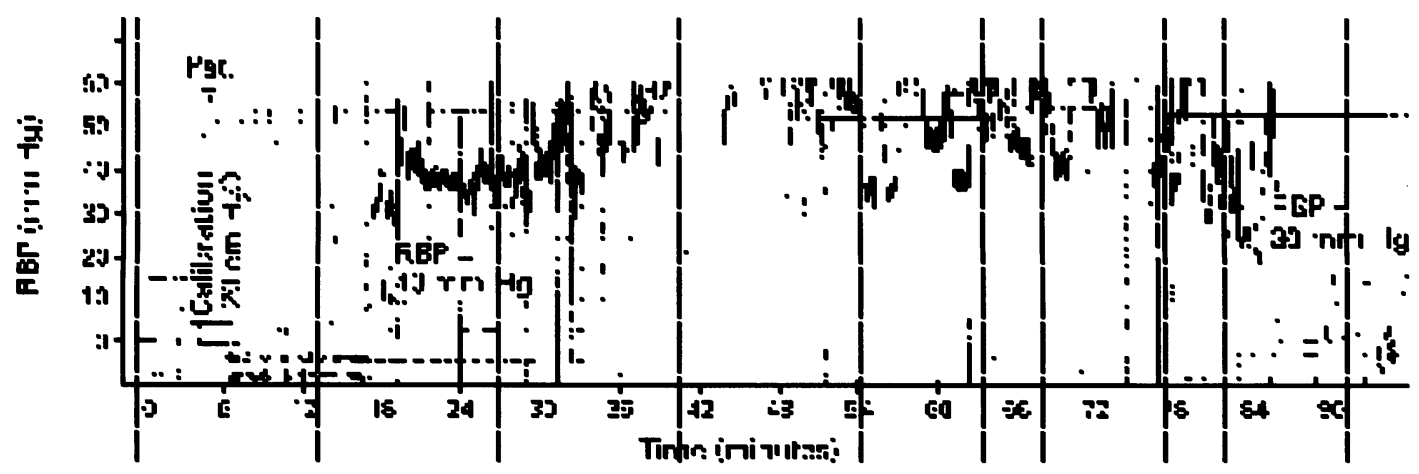

Figure 2 Retrobulbar pressures (RBPs) recorded during surgical decompression in patient no 7 with Graves' ophthalmopathy. After connecting a sterile pressure transducer catheter an initial RBP of plus or minus $7 \mathrm{~mm} \mathrm{Hg}$ was measured. Excessive peaks and roughness of the graphs is caused by spatula manipulation. Spatula force induced pressures of over $70 \mathrm{~mm} \mathrm{Hg}$. At the $78 \mathrm{th}$ minute of surgery incisions were made in the periorbit and the RBP decreased. 


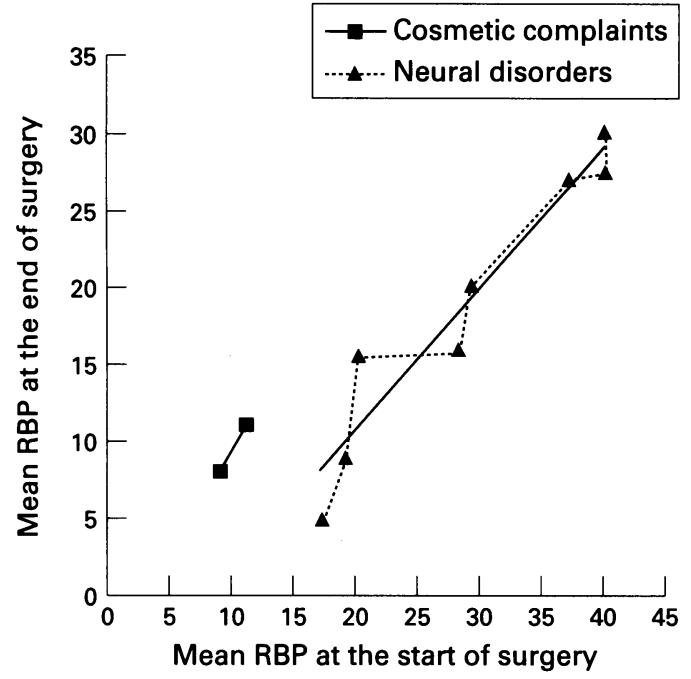

Figure 3 The relation between the mean retrobulbar pressures (RBPs) at the start of surgery and the pressures after wound closure in orbits operated for rehabilitative reasons and in patients with dysthyroid optic neuropathy (DON). A high correlation is seen between the start RBPs and the pressure decrease at the end of surgery $(p=$ $<0.001)$.

our patients a year before an ultimate stabilisation is attained.

Raised RBP above normal venous pressure may affect the vascularisation of intraorbital tissues by compressing the venous system, thus obstructing the venous outflow. This flow can also be influenced by muscle pressure upon the veins. ${ }^{29}$ The oxygenation of the orbital tissues will be impaired at the RBP levels measured, since the tissue pressure in the orbit equals and surpasses the maximum capillary perfusion pressure of $25-36 \mathrm{~mm} \mathrm{Hg} .{ }^{30}$ Once the RBP reaches $40 \mathrm{~mm} \mathrm{Hg}$, a progressive increase of intraorbital volume will not result in a further rise of the RBP. At this pressure all tissue fluids will pass easily through the capillary barrier and will be expelled from the orbit by the vessels.

The visual impairment in Graves' ophthalmopathy is generally believed to be the result of direct local pressure exerted by the swollen infiltrated muscles encroaching upon the optic nerve at the orbital apex. ${ }^{31}$ However, the substantially increased RBPs which we measure also can damage the optic nerve and other intraorbital nerve branches by direct pressure.

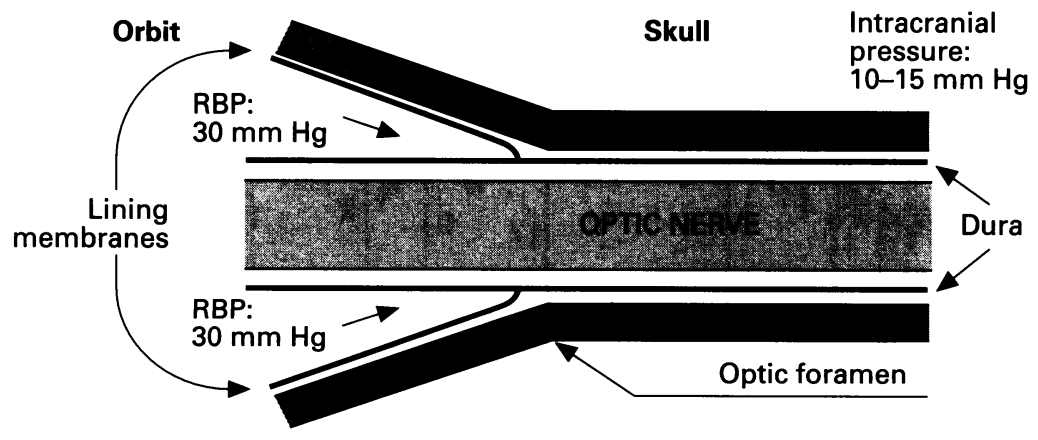

Compression of optic nerve at the orbital apex

Figure 4 Suggested mechanism which can cause optic nerve encroachment at increased retrobulbar pressure (RBP). The pressure difference at both sides of the optic canal will result in bulging of dura lined orbital tissue (fat), compressed backward around the optic nerve into the optic canal.
It has been found that compression of the vagus nerve in rabbits at $30 \mathrm{~mm} \mathrm{Hg}$ for 8 hours, induces inhibition of fast and slow anterograde as well as retrograde axonal transport. ${ }^{32-35}$ Consequently, we frequently observed improvement of the visual function after surgical decompression, even without removal of the bone fragments bordering the 'crowded' region. Among orbital surgeons it is not a standard procedure to remove part of the optic canal in orbital decompression for dysthyroid optic neuropathy. Furthermore, we consider it unlikely that a direct or diffuse pressure rise will be the only cause of impairment of the nerve function and came to the conclusion that secondary incarceration might also be involved. When RBP has reached higher levels than the intracranial pressure (which remains normal), optic nerve encroachment may occur near the optic foremen, caused by orbital tissues, bulging backward inside their lining periosteal membranes (Fig 4). Cadaver studies should be performed to prove the hypothesis mentioned above. In fact, in many coronal computed tomography scans of the orbital apex in Graves' ophthalmopathy a persistent narrow clear ring of low density (probably bulging adipose tissue) can be observed around the optic nerve. ${ }^{36}$ In this respect, an analogy may be opportune. The optic nerve compression could be comparable with medulla incarceration in the foremen magnum, seen with increased intracranial pressure. It may be concluded from our limited material, that ophthalmopathy with DON is associated with much higher pressures than without DON. Moreover it is evident that an RBP decrease can already be established at the end of the decompression surgery.

The force of 250 to $300 \mathrm{~g}$ against the intraorbital tissues exerted intraoperatively by a normally handled spatula resulted in transient RBP levels of over $70 \mathrm{~mm} \mathrm{Hg}$. At this pressure, dangerous impairment of the arterial vascularisation of the optic nerve and retina might ensue, especially in cases with preexisting vascular disorders.

Future studies using less invasive techniques to measure intraorbital pressure may allow an improvement in the timing of decompression surgery to prevent optic neuropathy in these patients.

The authors would like to thank Professor A Kijlstra for critically reading the manuscript.

1 Koornneef L, Schmidt ED, Van der Gaag R. The orbit: structure, autoantigens and pathology. In: Current issues in endocrinology and metabolism. Graves' ophthalmopathy. in endocrinology and metabolism. Graves' ophthalmopathy

Boston: Blackwell Scientific Publications, 1990:1-16.
2 Otto AJ, Spekreijse H. Intraorbital volume discrepancies Otto AJ, Spekreijse H. Intraorbital volume discrepancies
and intraorbital pressure. Int Ophthalmol 1987;11:113-4. $3 \mathrm{McCord} \mathrm{Jr}$ CD. Pressure-volume orbital measurements comparing decompression approaches. Ophthamic Plast Reconstruc Surg 1985;1:55-63.

4 Strobel J, Jacobi KW. Das Verhalten des intraorbitalen Druckes bei unterschiedlichem Volumen. Klin Monatsbl Augenheilkd 1987;191:449-51.

5 Stanley RJ, McCaffrey ThV, Offord KP, DeSanto LW. Space-occupying orbital lesions: can critical increases in inace-occupying orbital lesions: can critical increases in intraorbital pressur

6 Copper AC. An introduction to clinical orbitotonography. Thesis. Leiden, 1948.

7 Grossman EE, Burns ThA. Clinical use of orbitonometry. Am $\mathcal{f}$ Ophthalmol 1954;37:520-8. 
8 Kearns ThP, Henderson JW, Haines SF. Clinical orbitonometry in Graves' ophthalmopathy. Am $\mathcal{f}$ Ophthalmol nometry in G

9 Doege E. Das Zylinderorbitopiezometer. Thesis. Leipzig: Karl-Marx-Universität, 1979.

10 Frueh BR, Garber F, Grill R, Musch DC. Positional effects on exophthalmometer readings in Graves' eye disease. Arch Ophthalmol 1985;103:1355-6.

11 Frueh BR, Musch DC, Grill R, Garber FW, Hamby S. Orbital compliance in Graves' eye disease. Ophthalmology 1985;92:657-65.

12 McGowan HD, Hurwitz J, Gentles W. Orbitotonography, the dynamic assessment of orbital tension: 1 Results in subjects without known orbital disease. Can $\mathcal{F}$ Ophthalmol 1984;19:122-5.

13 Hurwitz JJ, McGowan HD, Gentles W, Weise RA, Victor W Orbitotonography, the dynamic assessment of orbital tension: 2 Results in patients with orbital disease. Can $\mathcal{f}$ Ophthalmol 1988;23:308-10.

14 Musch DC, Frueh BR, Landis JR. Observer variations between physician and lay readers. Ophthalmology 1985;92: 1177-80.

15 Buschmann W, Richter W, Kruse Ph, Neumann O. Functional results in Graves' ophthalmopathy following ophthalmo-rhinosurgical orbital decompression. Orbit 1986;5:117-21.

16 McCord Jr CD. Orbital decompression for Graves' disease. Exposure trough lateral canthal and inferior fornix incision. Ophthalmology 1981;88:533-41.

$17 \mathrm{McCord} \mathrm{Jr} \mathrm{CD}$. Current trends in orbital decompression. Ophthalmology 1985;92:21-33.

18 Fells P. Orbital decompression for severe dysthyroid eye disease. Br f Ophthalmol 1987;71:107-11.

19 Härting F, Koornneef L, Peeters HJF, Gillissen JPA. Fourteen years of orbital decompression in Graves' disease. A review of technique, results and complications. Orbit 1986;5:123-9.

20 Kennerdell JS, Maroon JC. An orbital decompression for severe dysthyroid exophthalmos. Ophthalmology 1982;89. 467-72.

21 Leone Chit, Piest KL, Newman RJ. Medial and lateral wall decompression for thyroid ophthalmopathy. Am $f$ Ophthalmol 1989;108:160-6.
22 Shorr N, Neuhaus RW, Baylis HI. Ocular motility problems after orbital decompression for dysthyroid ophthalmoafter orbital decompression for dysth. Ophthalmology 1982;89:323-8.

23 Warren JD, Spector JG, Burde R. Long-term follow-up and recent observations on 305 cases of orbital decompression for dysthyroid orbitopathy. Laryngoscope 1989;99:35-40.

24 Otto AI, Spekreijse H. Volume discrepancies in the orbit and the effect on the intraorbital pressure. Orbit 1989;8: 233-44.

25 Koornneef L, Mourits PM. Orbital decompression for decreased visual equity or for cosmetic reasons. Orbit 1988 ; 7:225-38.

26 Mourits PM, Koornneef L, Wiersinga WM, Prummel MF Berghout A, Gaag R van der. Orbital decompression for Graves' ophthalmopathy, by inferomedial plus lateral,

27 Moses RA, Lurie P, Grodzki WJ. Antero-posterior forces on the human eyeball. In: Lutjen-Decroll E, ed. Basic aspects of glaucoma research. Stuttgart: FK Schattauer Verlag, 1982 199-208.

28 Simonsz HJ, Härting F, Waal BJ de, Verbeeten BWJM. Sideways displacement and curved path of recti eye muscles. Arch Ophthalmol 1985;103:124-8.

29 Hudson HL, Levin L, Feldon SE. Graves exophthalmo unrelated to extraocular muscle enlargement. Ophthalmolunrelated to extraocular

30 Guyton AC. Textbook of medical physiology. Philadelphia: WB Saunders, 1986:357-9.

31 Neigel IM, Rootman J, Belkin RI, Nugent RA, Drance SM, Beattie CW, et al. Dysthyroid optic neuropathy. The crowded orbital apex syndrome. Ophthalmology 1988;95: 1515-21.

32 Quigley HA, Guy J, Anderson DR. Blockade of rapid axonal transport. Arch Ophthalmol 1979;97:525-31.

33 Dahlin LB. Nerve compression and axonal transport. Thesis. Sweden: University of Göteborg, 1986.

34 Johansson JO. Retrograde axoplasmic transport in rat optic nerve in vivo. What causes blockage at increased intraocular pressure? Exp Eye Res 1986;43:653-60.

35 Johansson JO. Inhibition and recovery of retrograde axoplasmic transport in rat optic nerve during and after elevated IOP in vivo. Exp Eye Res 1988;46:223-7.

36 Zonneveld FW. Computed tomography of the temporal bone and orbit. Thesis. Utrecht, 1987. 